\title{
SECOND MESIOBUCCAL CANALS IN MAXILLARY FIRST MOLARS DETECTED USING CONE-BEAM COMPUTED TOMOGRAPHY
}

\section{Tehmina Marwat ${ }^{1,2 \otimes}$,Nighat Shafiq ${ }^{1,3}$, Wajiha Qamar ${ }^{1,4}$}

\begin{abstract}
OBJECTIVE: To determine the numbers of second mesiobuccal canals of first permanent maxillary molars by Cone-Beam Computed Tomography (CBCT).

METHODS: In this cross-sectional study, data of patients requiring $C B C T$ images as part of their dental procedures were retrieved from the database of the radiology department of Sardar Begum Dental College, Peshawar, Pakistan. CBCT images of 100 maxillary Ist molars from 2016 to 2018 were selected by using consecutive sampling technique. Selection criteria for teeth were no prior endodontic treatment and roots formation completed, while teeth with open root apices and pathology were excluded. All teeth were analyzed in three planes (sagittal, axial, and coronal) and canal numbers per root were recorded. Descriptive statistics were computed in SPSS 20.0. Stratification was done for canals number in maxillary Ist molar among genders and age groups. Post, stratification Chi-Square/Fisher Exact test was applied to see effect modification.
\end{abstract}

RESULTS: The mean age of patients was $27.4 I \pm 13.22$ years. Second mesiobuccal canal (MB2) was present in $56(56 \%)$ cases. Frequency of second mesiobuccal canal was more in female patients $(n=29 / 40 ; 72.5 \%)$ than male patients $(n=27 / 60 ; 45 \%)$ [ $p=0.007]$. Overall, the most common age group was $10-25$ years $(57 \%)$ followed by $26-50$ years $(34 \%)$. Frequency of second mesiobuccal canal was $45.6 \%(n=26 / 57), 61.8 \%(n=21 / 34) \& 100 \%(n=9 / 9)$ in age groups $10-25$ years, 26-50 years \& $>50$ years, respectively $(p=.004)$.

CONCLUSION: A high frequency was recorded for second mesiobuccal canal in upper first molars and a significant association was noted for second mesiobuccal canal with gender and age group.

KEY WORDS: Canal Configuration (MeSH); Second mesiobuccal canal (Non$\mathrm{MeSH})$; Maxillary first molar (Non-MeSH); Extra canal (Non-MeSH); Missed canal (Non-MeSH); Cone-Beam Computed Tomography (MeSH); Molar (MeSH).

THIS ARTICLE MAY BE CITED AS: Marwat T, Shafiq N, Qamar W. Second mesiobuccal canals in maxillary first molars detected using conebeam computed tomography. Khyber Med Univ J 2020;12(2):113-6. DOI: $10.35845 / \mathrm{kmuj} .2020 .19244$.

\section{INTRODUCTION}

Thour hough the dental pulp is physically smaller in size, an inflammation of dental pulp of teeth causes unbearable and merciless pain to a person.' The dental pulp due to its unique location can be both difficult to locate and extirpate. So, a deep knowledge of root canal morphology and anatomy is of utmost importance when performing endodontic treatment. ${ }^{1,2}$

One of the reason for root canal treatment failure in upper molars is the lack of ability to locate second mesiobuccal canal (MB2). ${ }^{3}$ The location and treatment of the MB2 in maxillary $I^{\text {st }}$ molars have been facilitated due to improvement in illumination and magnificatntecnology. ${ }^{4}$ Morphology of maxillary molars is complex. Most of the investigations reported $50 \%$ prevalence of extra canal (MB2). However, according to a research the occurrence of $\mathrm{MB} 2$ in upper first molars is up to $63 \%$. $^{7}$ And re-endodontic treated teeth were containing more non-located MB2 canals, which shows that failure to treat the MB2 canals
I. Department of Oral Biology, Sardar Begum Dental College, Gandhara University, Peshawar Pakistan

2. Department of Oral Biology, Khyber Medical University Institute of Dental Sciences (KMU-IDS), Kohat, Pakistan

3. Department of Oral Biology, Khyber College of Dentistry, Peshawar, Pakistan

4. Department of Oral Biology, Dental Section Bacha Khan Medical College, Mardan, Pakistan

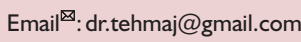

Contact \# : +92-312-5850450

$\begin{array}{ll}\text { Date Submitted: } & \text { April I2, 2019 } \\ \text { Date Revised: } & \text { May 26, 2020 } \\ \text { Date Accepted: } & \text { May 30, 2020 }\end{array}$

results in bad prognosis. ${ }^{8}$ In recent times, Cone-Beam Computed Tomography (CBCT) images have been introduced which is more accurate and provide three dimensions anatomic details for diagnosis and treatment planning before starting endodontic therapy. 9.10

The rationale of this study was that the location second canal (MB2) in the mesiobuccal root is very difficult because the excess dentin is deposited at the canal orifice and also it is difficult to visualize maxillary molars access cavity. If $M B 2$ is missed while performing root canal treatment then can results in persistent pain and failure of root canal treatment. As CBCT provides three-dimensional (3-D) imaging and chance of missing MB2 is almost negligible; therefore, this study can show the real frequency of MB2 in our population. Incidence of a MB2 in the mesial root of first molars is not investigated in population of Peshawar. The frequency rate will redirect the attention of clinicians to its presence and not to miss canal during endodontic treatment. The objective of this study was to find out the frequency of a second mesiobuccal canal of maxillary first molars in patients requiring $\mathrm{CBCT}$ images as part of their dental procedures in local hospital of Peshawar Pakistan.

\section{METHODS}

In this descriptive cross-sectional, study CBCT images of 100 maxillary first molars of Peshawar population (60 
TABLE I: FREQUENCY OF GENDER, SIDE OF UPPER FIRST MOLAR, SECOND MESIOBUCCAL CANAL AND AGE CATEGORIES

\begin{tabular}{|l|l|c|c|}
\hline \multicolumn{1}{|c|}{ Variables } & Categorical Variable & Frequency $(\mathbf{n}=100)$ & Percentage \\
\hline \multirow{2}{*}{ Gender } & Male & 60 & 60 \\
\cline { 2 - 4 } & Female & 40 & 40 \\
\hline \multirow{2}{*}{ Side of Upper First Molar } & Right & 44 & 44 \\
\cline { 2 - 4 } & Left & 56 & 56 \\
\hline \multirow{2}{*}{ Second Mesiobuccal Canal } & Yes & 56 & 56 \\
\cline { 2 - 4 } & No & 44 & 44 \\
\hline \multirow{3}{*}{ Age groups (years) } & $10-25$ & 57 & 57 \\
\cline { 2 - 4 } & $26-50$ & 34 & 34 \\
\cline { 2 - 4 } & greater than 50 & 9 & 9 \\
\hline
\end{tabular}

TABLE II: FREQUENCY OF SECOND MESIOBUCCAL CANAL STRATIFIED BY GENDER

\begin{tabular}{|c|c|c|c|c|c|c|}
\hline \multirow{3}{*}{$\begin{array}{c}\text { Gender of } \\
\text { patient }\end{array}$} & \multicolumn{4}{|c|}{ Second Mesiobuccal Canal } & \multirow{3}{*}{$x^{2}$} & \multirow{3}{*}{ P-value } \\
\hline & \multicolumn{2}{|c|}{ Yes $(n=56)$} & \multicolumn{2}{|c|}{ No $(n=44)$} & & \\
\hline & Frequency & Percentage & Frequency & Percentage & & \\
\hline Male $(n=60)$ & 27 & 45.0 & 33 & 55.0 & \multirow{2}{*}{7.366} & \multirow{2}{*}{0.007} \\
\hline Female $(n=40)$ & 29 & 72.5 & 11 & 27.5 & & \\
\hline
\end{tabular}

TABLE III: FREQUENCY OF SECOND MESIOBUCCAL CANAL STRATIFIED BY AGE CATEGORIES

\begin{tabular}{|c|c|c|c|c|c|}
\hline \multirow{3}{*}{$\begin{array}{l}\text { Age groups } \\
\text { (years) }\end{array}$} & \multicolumn{4}{|c|}{ Second Mesiobuccal Canal } & \multirow{3}{*}{ P-value } \\
\hline & \multicolumn{2}{|c|}{ Yes $(n=56)$} & \multicolumn{2}{|c|}{ No $(n=44)$} & \\
\hline & Frequency & Percentage & Frequency & Percentage & \\
\hline $10-25(n=57)$ & 26 & 45.6 & 31 & 54.4 & \multirow{3}{*}{0.004} \\
\hline $26-50(n=34)$ & 21 & 61.8 & 13 & 38.2 & \\
\hline$>50(n=9)$ & 9 & 100 & 0 & 0 & \\
\hline
\end{tabular}

males and 40 females) were retrieved from the database of the radiology department of Sardar Begum Dental College, Peshawar, Pakistan. Ethical approval was obtained from Hospital Ethical Research Committee. The gender distribution was not equal due to existing pattern of the data that was retrieved consecutively from the images based on date of admission. These patients were referred to radiology department between 2016 and 2018 and needed CBCT images as part of their dental procedures. The selected teeth were upper first permanent molars with no prior endodontic treatment and roots formation completed. Teeth with root apices open and pathology were excluded. All teeth were analyzed in sagittal, axial, and coronal planes ${ }^{2}$ and canals number per root were recorded.

Statistical analysis was done in SPSS 20.0. Mean and standard deviation was calculated for numerical variables like age. Percentages and frequencies were calculated for categorical variables like gender and number of canal in maxillary first molar. Stratification was done for number of canals in maxillary first molar among genders and age groups. Post stratification Chi-Square/Fisher-Exact test was applied to see effect modification and $\mathrm{p}$-value $\leq 0.05$ was considered significant.

\section{RESULTS}

The mean age of patients was $27.41 \pm 13.22$ years. Of total I00 CBCT images, $60(60 \%)$ were of males and 40 $(40 \%)$ were of females. In majority of cases $(n=56 ; 56 \%)$ maxillary first molar CBCT scans were available for left side. First mesiobuccal canal were present in all cases. The overall frequency for second mesiobuccal canal (MB2) was 56 (56\%). Most common age group was 10-25 years (57\%) [Table: I]. Frequency of second mesiobuccal canal was more common on right side $(n=42,95.5 \%)$.

Frequency of second mesiobuccal canal was more in female patients $(n=29 / 40$; $72.5 \%)$ than male $(n=27 / 60 ; 45 \%)$ patients $(p=0.007)$ [Table II].

With increasing age, the frequency of second mesiobuccal canal was shown to be decreased. Frequency of second mesiobuccal canal was $45.6 \%$ $(n=26 / 57)$ and $61.8 \%(n=21 / 34)$ in age groups $10-25$ years and $26-50$ years respectively $(p=.004)$ [Table: III].

\section{DISCUSSION}

In this study about the frequency of MB2 canal in upper $I^{\text {st }}$ permanent molar by CBCT method showed that MB2 was found in $56 \%$ overall and more in females than males $(P=.007)$. With increasing age the frequency of second mesiobuccal canal was shown decrease $(P=.004)$ and $M B 2$ more common on right side $(\mathrm{P}<0.00 \mathrm{I})$.

CBCT is far better in locating root canal instead of conventional x-ray. Conventional $\mathrm{X}$-rays can combat the problem of superimposition. CBCT is three dimensional in nature and can give three views (sagittal, axial and coronal) plus one three 3-D reconstructed view. The clinicians can easily observe and measured all the area in the scan by moving the computer mouse."

For successful root canal treatment the canal identification is critical. Karabucak, et al. ${ }^{12}$ in a retrospective cohort study assessed frequency of undiagnosed canals in root canal treated teeth using CBCT scans. They reported that in case of missed canal the tooth was 4.38 times more likely to have associated periapical pathology. They further found, the MB2 canal was the most often missed canal.

Our findings showed that the overall frequency for second mesiobuccal canal (MB2) was $n=56(56 \%)$. This shows that in more than half cases there is second canal present.

A study by Agwan, et al. ${ }^{13}$ on Saudi Arabian population determined the frequency of MB2 in maxillary $I^{\text {st }}$ molar. They used surgical telescopes, headlamps along with modified access preparations. Their results showed that 
$45 \%$ cases have second mesiobuccal canal in mesiobuccal root. The higher frequency in our study may due to the fact that we used CBCT method which is more effective in locating and detecting the MB2.

A CBCT based study by Hiebert, et al. ${ }^{2}$ on MB2 canal occurrence in upper maxillary first molar in California reported that the prevalence of MB2 canals was found in $69 \%$ patients. The frequency for MB2 canal in their study is much higher than our study. This may be due to many reasons like sample size, experience with $\mathrm{CBCT}$ interpretation, genetic and ethnic variations.

A recent study by Alfouzan, et al. ${ }^{14}$ on Saudi population on MB2 canal occurrence in upper maxillary first molar using $C B C T$ reported that the frequency of MB2 canal was $70 \%$. This frequency is much higher from our study. This variation in results can be attributed to racial differences, age of the participants, and experience of operator etc. In younger age, the canals are patent and are not calcified so more easily located.

In a study by Goldman, et al. ${ }^{15}$ showed that different individuals interpret images differently. Parker, et al. ${ }^{16}$ assessed various categories of individuals in detecting periapical pathology in CBCT images and compared this with oral and maxillofacial radiologists interpretation. They reported that a correlation exist between clinician's experience level for proper diagnosis. In another investigation ${ }^{17}$, it was found that dentist will be more facilitated to assess endodontic problems using CBCT imaging compared with other experts.

In the current study, frequency of MB2 canal was more in female gender than males. These variations for frequency of second mesiobuccal canal among genders were statistically significant. similar results were reported by Saudi Arabian study. ${ }^{13}$

Our finding showed that with increase in age of the population, the frequency of MB2 also increases. It is against the fact that as the age advances the canals become calcified and obliterated as shown in a study. ${ }^{13}$
This is the first of kind of study in Peshawar to determine the frequency of MB2 canal in maxillary first molar using $\mathrm{CBCT}$. This can help the clinician to know the real frequency of MB2. However, our study is of small sample, single center and retrospective design. So it is recommended to read the results with caution.

\section{CONCLUSION}

A high frequency was recorded for second mesiobuccal canal in upper first molars and a significant association was noted for second mesiobuccal canal with gender and age group.

\section{REFERENCES}

I. Vertucci FJ. Root canal morphology and its relationship to endodontic procedures. Endod Topic 2005; I0(I):3-29. DOI: 10.1III /j. I60I-I546.2005.00I29.x.

2. Hiebert BM, Abramovitch K, Rice $D$, Torabinejad M. Prevalence of second mesiobuccal canals in maxillary first molars detected using cone-beam computed tomography, direct occlusal access, and coronal plane grinding. J Endod 2017;43(I0): I7II-5. DOI: I0.1016/ j.joen.2017.05.0II.

3. Žemaitienè $M$, Grigalauskienè R, Vasiliauskienè I, Saldūnaité K, Razmienè J, Slabšinskienè E. Prevalence and severity of dental caries among 18-year-old Lithuanian adolescents. Medicina (Kaunas) 2016;52(I):54-60. DOI: 10.1016/j.medici.2016.01.006.

4. Carr A, Brown D. McCracken's removable partial denture. 13th ed. Mosby, Norway: Elseviere;20II. [Accessed on: March 10, 2019]. Available from URL: https://www.elsevier.com/books/m ccrackens-removable-partialprosthodontics/carr/978-0-32333990-2.

5. Wolcott J, Ishley D, Kennedy W, Johnson S, Minnich S, Meyers J. A 5 yr clinical investigation of second mesiobuccal canals in endodontically treated and retreated maxillary molars. J Endod 2005;3I(4):262-4. DOI: 10.1097/
0I.don.0000 I 4058I.38492.8b.

6. Hameed MH, Khan FR. Diagnosis of second mesiobuccal canal in maxillary first molars among patients visiting a tertiary care hospital. Int J Biomed Sci 20।5; I I (2): 107-8.

7. Medhat F. The prevalence of a second mesiobuccal canal of maxillary first and second molars using CBCT among egyptian population: a cross sectional study [Protocol submitted]. Cairo: Misr International University;20I7. [Accessed on: March 10, 2019]. Available from URL: https://clinicaltrials.gov/ProvidedD ocs/73/NCT03225573/Prot_000.p df.

8. Silva EJNL, Nejaim Y, Silva AI, Haiter-Neto F, Zaia AA, Cohenca N. Evaluation of root canal configuration of maxillary molars in a Brazilian population using conebeam computed tomographic imaging: an in vivo study. J Endod 2014;40(2):173-6. DOI: $10.1016 / j$ .joen.2013.10.002.

9. Hartwell G, Bellizzi R. Clinical investigation of in vivo endodontically treated mandibular and maxillary molars. J Endod 1982;8(I2):555-7. DOI: 10.1016/ S0099-2399(82)800I6-2.

10. Hasan M, Khan FR. Determination of frequency of the second mesiobuccal canal in the permanent maxillary first molar teeth with magnification loupes $(\times 3.5)$. Int J Biomed Sci 20 I 4; I 0(3):20 I -7.

II. Durack C, Patel S. Cone beam computed tomography in endodontics. Braz Dent J 2012; 23(3):| |79-91.

12. Karabucak B, Bunes A, Chehoud C, Kohli MR, Setzer F. Prevalence of apical periodontitis in endodontically treated premolars and molars with untreated canal: a cone-beam computed tomography study. J Endod 2016;42(4):538-4I. DOI: 10.1016/j.joen.2015.12.026.

13. Agwan AS, Sheikh Z, Dh D, Rashid $\mathrm{H}$. Canal configuration and the prevalence of second mesiobuccal 
canal in maxillary first molar of a Saudi sub-population. J Pak Dent Assoc 2015;24(04): 182-9.

14. Alfouzan K, Alfadley A, Alkadi L, Alhezam A, Jamleh A. Detecting the second mesiobuccal canal in maxillary molars in a Saudi Arabian Population: a micro-ct study. Scanning 2019;2019(I):I-6. DOI: I0.1I55/2019/9568307.

15. Goldman M, Pearson AH, Darzenta
N. Endodontic success-who's reading the radiograph? Oral Surg Oral Med Oral Pathol 1972;33(3):432-7. DOI: 10.1016/ 0030-4220(72)90473-2.

16. Parker JM, Mol A, Rivera EM, Tawil PZ. Cone-beam computed tomography uses in clinical endodontics: observer variability in detecting periapical lesions. J Endod 20I7;43(2):184-7. DOI: 10.1016 /j.joen.2016.10.007
17.Rodríguez G, Abella F, DuránSindreu F, Patel S, Roig M. Influence of cone-beam computed tomography in clinical decision making among specialists. J Endod 2017;43(2):194-9. DOI: 10.1016/] .joen.2016.10.012.

\section{AUTHORS' CONTRIBUTIONS}

Following authors have made substantial contributions to the manuscript as under:

TM: Conception and study design, acquisition of data, drafting the manuscript, critical review, final approval of the version to be published.

NS \& WQ: Analysis and interpretation of data, drafting the manuscript, final approval of the version to be published.

Authors agree to be accountable for all aspects of the work in ensuring that questions related to the accuracy or integrity of any part of the work are appropriately investigated and resolved.

(c) (i) \$

BY NC

\section{CONFLICT OF INTEREST}

Authors declared no conflict of interest GRANT SUPPORT AND FINANCIAL DISCLOSURE NIL
This is an Open Access article distributed under the terms of the Creative Commons Attribution-Non Commercial 2.0 Generic License.

KMUJ web address: www.kmuj.kmu.edu.pk Email address: kmuj@kmu.edu.pk 